\title{
Building Vibration Prediction Induced by Moving Train with Random Forest
}

\author{
Jinbao Yao $\mathbb{D i D}^{1}$ and Lei Fang ${ }^{1,2}$ \\ ${ }^{1}$ School of Civil Engineering, Beijing Jiaotong University, Beijing 100044, China \\ ${ }^{2}$ Ma'anshan Economic and Technological Development Zone, Ma'anshan, Anhui 243000, China \\ Correspondence should be addressed to Jinbao Yao; jbyao@bjtu.edu.cn
}

Received 29 October 2020; Revised 6 January 2021; Accepted 22 January 2021; Published 9 February 2021

Academic Editor: Ronghui Zhang

Copyright (c) 2021 Jinbao Yao and Lei Fang. This is an open access article distributed under the Creative Commons Attribution License, which permits unrestricted use, distribution, and reproduction in any medium, provided the original work is properly cited.

\begin{abstract}
This paper adopts a combination of numerical simulation, field test, and Random Forest to predict the building vibration induced by moving train. First, a three-dimensional finite element model based on train-track-site soil-building system is established, and the track dynamic reaction force calculated by the train-track model is applied as an excitation to the site. On the soil-building model, this paper analyzes the influence of train speed, axle load, site soil characteristics, and distance from the building on the vibration of the building caused by the train. With the Random Forest, these different influencing factors are used as inputs, and the building vibration is the output. Thus, the prediction model of the building vibration caused by moving train is established. The prediction accuracy can be tested with the measured data. The results show that this prediction method can provide a higher prediction accuracy with the maximum error (less than 6.41\%) and the average error (less than 2.29\%). This method overcomes the shortcomings of traditional prediction methods and improves the accuracy of vibration prediction.
\end{abstract}

\section{Introduction}

Rail transit has developed rapidly in China in recent years due to its advantages of large capacity, high speed, and low transportation cost. High-speed rail transit also causes more and more serious environmental vibration problems. Vibration damage has become one of the seven major public hazards [1]. Environmental vibration will not only cause serious insomnia, anxiety, and other negative effects on individuals but also affect the accuracy of precision instruments. The research on environmental vibration caused by rail transit has attracted many scholars' attention [2-5].

The building vibration induced by moving train has also been studied by some literature. Kouroussis et al. [6] used finite element modeling for evaluating the ground waves propagation and a coupled lumped mass model of the soil to avoid computational resources. And then they proposed modal analyses of the vehicle and the building to acquire the effects of seismic wave amplification. Coulier et al. [7] tried to predict the vibrations in buildings by railway traffic. In their study, a coupled finite element-boundary element methodology is used to analyze the interaction between a building and a railway tunnel. They found that the interaction between a source at depth and a receiver mainly affects the power flow distribution. This mainly due to the fact that the distance between source and receiver is smaller than the dilatational wavelength in the soil. Lopez-Mendoza et al. [8] proposed a scoping model to predict building vibration induced by railway traffic. The input of the model is the data of ground-borne vibration as model input. Galvin et al. [9] also adopted scoping assessment to predict freefield vibrations by railway traffic. Ding et al. [10] aimed to study the soil vibration response of a pile group to reflect the group-soil vibration induced by railway traffic. Paneiro et al. [11] measured ground vibrations caused by urban rail transit, trained on the measured data through artificial neural networks, and used artificial neural networks to predict vibrations. However, the influence of soil characteristics on vibration propagation is not considered in this 
paper. Connolly et al. $[12,13]$ proposed a vibration prediction method.

Recently, some researchers [14-16] used swarm intelligence to predict the vibration induced by railway traffic. Jayawardana et al. [17] used artificial neural network (ANN) to predict the vibration isolation effect of double-layer vibration isolation trenches and developed a general prediction model. Yao et al. $[18,19]$ used the support vector machine to predict the vibration of the building through the measured data and the finite element analysis method. Fang et al. [20] used numerical simulation results and field test data to train artificial neural networks to improve the accuracy of vibration prediction. Their prediction model studied the vibration of the site soil but did not analyze the vibration of the building.

This paper tries to propose a vibration prediction model based on Random Forest. Then the numerical simulation method and the field test method are used to improve the prediction performance. The remainder of this paper is organized as follows. Section 2 describes our numerical analysis model which consists of a train-track model, a site soil model, and a building model. Building vibration influence factors are discussed in Section 3, followed by a description of the prediction model based on Random Forest in Section 4. Finally, Section 5 concludes this paper.

\section{Numerical Analysis Model}

A three-dimensional model of the train-track-site soilbuilding system was established to shorten the calculation time. The whole system is divided into three subsystem models: train-track, site soil, and building models. Using the train-track system model, the vertical dynamic reaction force of the track on the site soil can be obtained when the train is moving. The vertical dynamic reaction force is loaded on the site soil model, and the vibration response of any point in the site can be obtained through calculation. The vibration of the building in the site soil model to the foundation of the building can be obtained based on the vibration from each point of the building.

2.1. Train-Track Model. The train is simulated as a multirigid and multidegree-of-freedom system with moving on the track at a certain speed. Since the impact of vertical vibration on the surrounding environment is greater than that of lateral vibration, this paper only considers the impact of vertical vibration on buildings. A train carriage rigidly connected to the rail using Euler beam model simulation, discrete point support manner, the base rail using ballasted track model, and the Hertz nonlinear elastic contact are used to analyze the coupling between the train and the track [21].

2.1.1. Train Model. The train model is composed of multiple vehicles, and each vehicle is considered to be composed of multiple rigid bodies with concentrated mass, including carriages, bogies, wheelsets, springs, and dampers. The train calculation model is shown in Figure 1. The parameters of each component are shown in Table 1.
The train and the bogie, the bogie, and the wheels are all connected by springs and dampers to simulate the suspension system of the train. In the model, the pitch $(\beta c)$ and float $(\mathrm{Zc})$ of the train, the pitch $(\mathrm{Zt} 1, \mathrm{Zt} 2)$ and float $(\beta \mathrm{t} 1, \beta \mathrm{t} 2)$ of the bogie, the vertical movement of the four wheels $\left(Z_{w i}\right.$, $i=1 \sim 4$ ), a total of 10 degrees of freedom, and Lagrangian equation are used to establish the train's motion equation, as shown in formula (1):

$$
\frac{\mathrm{d}}{\mathrm{d} t}\left(\frac{\partial T}{\partial q_{k}}\right)-\frac{\partial T}{\partial q_{k}}+\frac{\partial V}{\partial q_{k}}+\frac{\partial Q}{\partial q_{k}}=0 .
$$

In the formula, $T, V$, and $Q$, respectively, represent the total kinetic energy, total elastic potential energy, and total damping dissipation energy of the motion system.

Based on the Lagrangian equation, the equation of train body, bogie, and wheelset can be established.

The motion equation of the $i$-th carriage and its corresponding two bogies is shown in equation (2):

$$
\mathrm{M}_{i} \ddot{Z}_{i}-C_{i} \dot{Z}_{i}+K_{i} Z_{i}=P_{i}(t), \quad i=1,2, \ldots, N_{v} .
$$

In formula (2), $Z_{i}$ is the displacement vector of the $i$-th train; $P_{i}(t)$ is the external excitation force of the $i$-th train; $M_{i}$, $C_{i}$, and $K_{i}$, respectively, represent the mass of the $i$-th carriage, damping, and density.

In the train-track model, the random vibration of the train is simulated by inputting the track irregularity spectrum. The track irregularity spectrum is based on the low interference power density function of German high-speed line track irregularity [22], which is obtained by inverse Fourier transform with MATLAB software.

2.1.2. Track Model. This paper uses the form of ballasted track. The track system consists of four parts: rails, sleepers, track beds, and subgrades, which are simulated as a threelayer discrete model. The track is regarded as an Euler beam model supported by discrete points, which are discrete according to the support points of the sleepers. Each element is composed of two mass units $\left(M_{s i}\right.$ and $\left.M_{b i}\right)$ and three-layer spring damping units $\left(K_{p i}\right.$ and $C_{p i}, K_{b i}$ and $C_{b i}$, and $K_{f i}$ and $\left.C_{f}\right)$. Adjacent units are connected by shear spring damping $\left(K_{w i}\right.$ and $\left.C_{w i}\right)$. The model is shown in Figure 2.

2.2. Site Soil Model. The finite element analysis software ANSYS was used to establish the soil calculation model of the site. In order to shorten the calculation time, the site soil model was simplified. The line length was $48.5 \mathrm{~m}$, vertical track width was $120 \mathrm{~m}$, and vertical track depth was $52.9 \mathrm{~m}$. There is a two-layer direction perpendicular to the track; the size of the model is shown in Figure 3.

In the actual working conditions of the site, the site soil is a multilayer structure, and the characteristics of each layer of soil are different. In the numerical simulation, in order to reduce the calculation conditions and shorten the calculation time, using formula (3), the weighted average method is used to convert multiple layers of soil into two layers of soil [23] for simplified calculation. The converted site soil parameters are shown in Table 2. 


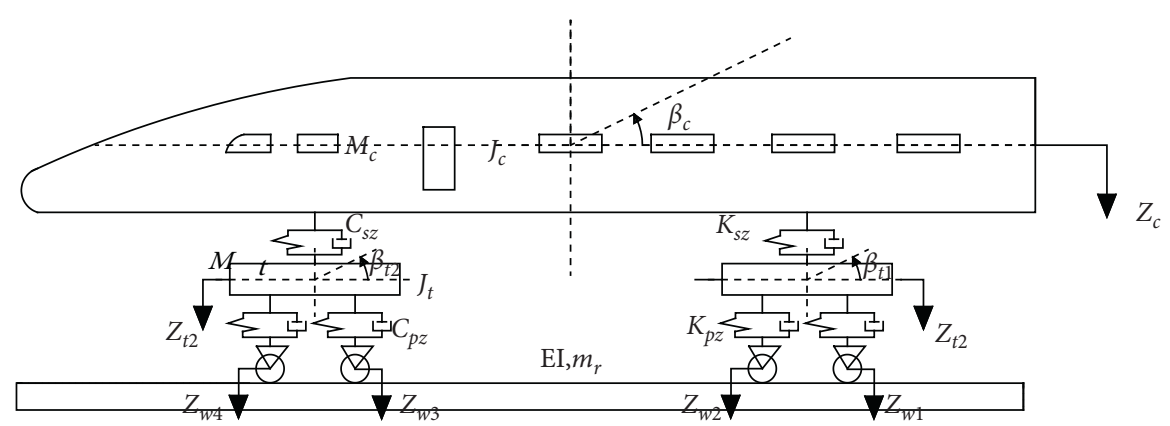

FIgURE 1: Train calculation model.

TABLE 1: Calculation parameters of train model.

\begin{tabular}{lccc}
\hline Name & Unit & CRH2 (locomotive) & CRH2 (car) \\
\hline Overall vehicle mass $M_{c}$ & $\mathrm{~kg}$ & 3160 & 30500 \\
Bogie quality $M_{t}$ & $\mathrm{~kg}$ & 3200 & 2600 \\
Wheelset quality $M_{w}$ & $\mathrm{~kg}$ & 2000 & $1.867 \times 10^{6}$ \\
Moment of inertia of vehicle body nodding $J_{c}$ & $\mathrm{~kg} \cdot \mathrm{m}^{2}$ & $1.753 \times 10^{3}$ & $1.279 \times 10^{6}$ \\
Moment of inertia of bogie nodding $J_{t}$ & $\mathrm{~kg} \cdot \mathrm{m}^{2}$ & $2.352 \times 10^{6}$ & $1.424 \times 10^{3}$ \\
Primary suspension stiffness (per axle) $K_{p z}$ & $\mathrm{~N} / \mathrm{m}$ & $1.96 \times 10^{5}$ & $2.488 \times 10^{6}$ \\
Primary suspension damping (per axle) $C_{p z}$ & $\mathrm{~N} \cdot \mathrm{s} / \mathrm{m}$ & $2.291 \times 10^{6}$ & $3.92 \times 10^{5}$ \\
Secondary suspension stiffness $K_{s z}$ & $\mathrm{~N} / \mathrm{m}$ & $1.174 \times 10^{6}$ & $1.982 \times 10^{6}$ \\
Secondary suspension damping $C_{s z}$ & $\mathrm{~N} \cdot \mathrm{s} / \mathrm{m}$ & 25 & $1.96 \times 10^{6}$ \\
Vehicle length $l$ & $\mathrm{~m}$ & 17.5 & 25 \\
Vehicle spacing $l_{c}$ & $\mathrm{~m}$ & 2.5 & 17.5 \\
Wheelbase of bogie $l_{t}$ & $\mathrm{~m}$ & 0.43 & 2.5 \\
Wheel rolling circle radius $R$ & $\mathrm{~m}$ & 0.43 \\
\hline
\end{tabular}

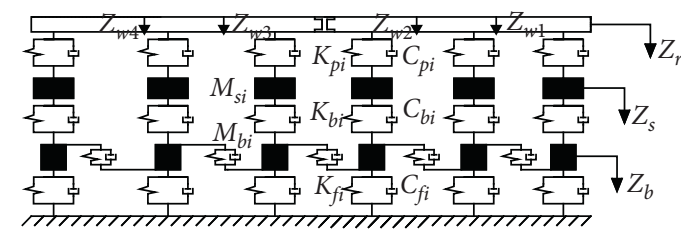

Figure 2: Track calculation model.

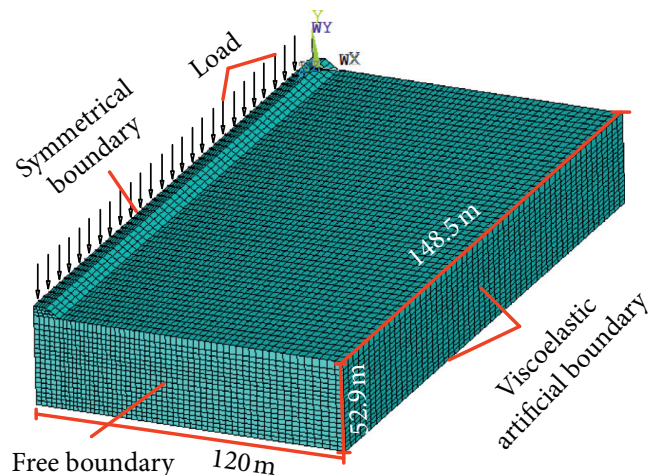

Figure 3: Three-dimensional finite element model of site soil. 
TABLE 2: Site soil characteristic parameters.

\begin{tabular}{lccccc}
\hline Soil layer & Thick $(\mathrm{m})$ & Bearing capacity $(\mathrm{kPa})$ & Compression modulus $(\mathrm{MPa})$ & Water content $(\%)$ & Density $\left(\mathrm{g} / \mathrm{cm}^{3}\right)$ \\
\hline Layer 1 & 9.7 & 148.1 & 17.7 & 21.8 & 1.8 \\
Layer 2 & 38.1 & 178.3 & 16.9 & 23.3 & 1.9 \\
\hline
\end{tabular}

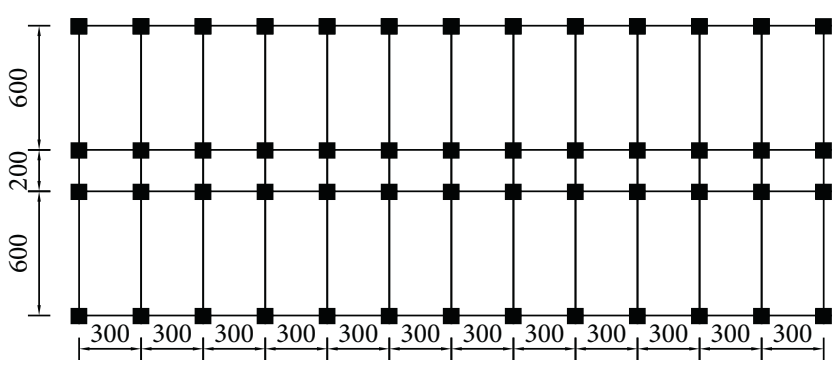

FIgure 4: The standard layout of the building.

$$
E_{\text {eq }}=\frac{\sum H_{i} E_{i}}{\sum H_{i}}
$$

The right boundary and the lower boundary in the model adopt a three-dimensional uniform viscoelastic artificial boundary to reduce the impact of vibration wave reflection at the boundary on the vibration response [24]. The front boundary and the rear boundary are regarded as free boundaries. The left boundary adopts a symmetrical boundary.

2.3. Building Model. The building is a frame structure type with 6 stories, each of which is three meters high. The total height is $18 \mathrm{~m}$, the length is $3 * 12=36 \mathrm{~m}$, and the width is $1.4 \mathrm{~m}$. The span is $6 \mathrm{~m}$; the intermediate span is $2 \mathrm{~m}$. The building consists of three parts: beam, column, and plate. The cross-sectional size of the column is $500 \mathrm{~mm} \times 500 \mathrm{~mm}$; the cross-sectional size of the main beam of the house frame is $350 \mathrm{~mm} \times 600 \mathrm{~mm}$; the cross-sectional size of the secondary beam is $350 \mathrm{~mm} \times 500 \mathrm{~mm}$; the plate thickness is $10 \mathrm{~cm}$; the building layout is shown in Figure 4 .

The frame beams and columns of the building are made of C25, and the floor slab is made of C20 concrete. The building damping ratio $\xi_{c}=0.05$. The finite element model of the building is shown in Figure 5. The large mass method is used to load the building, and the spring elastic connection is used between the concentrated mass and the base node of the building without considering the damping effect. The spring stiffness is calculated according to formulae (4) and (5):

$$
\begin{gathered}
K_{x}=\frac{\lambda\left(-k_{\gamma}^{\prime 2} T e^{-r^{\prime} z}+r^{\prime} T e^{-r^{\prime} z}\right) e^{i\left(-k_{\gamma}^{\prime}\right)}+2 \mu^{\prime}\left[-k_{\gamma}^{\prime 2} \mathrm{Te}^{-r^{\prime} z}+i k_{\gamma}^{\prime} s^{\prime}\left(T b / 2 i k_{\gamma} s\right) e^{-s^{\prime} z}\right]+m^{\prime}\left(i w^{\prime 2} k_{\gamma}^{\prime} T-w^{\prime 2} s\left(T b / 2 i k_{\gamma} s\right) e^{-s^{\prime} z}\right)}{\left(-i k_{\gamma} e^{-r z}-s\left(b / 2 i k_{\gamma} s\right) e^{-s z}\right)+\left(i k_{\gamma} \operatorname{Re}^{-r z}+s\left(R b / 2 i k_{\gamma} s\right) e^{-s z}\right)-\left(i k_{\gamma}^{\prime} T e^{-r, z}-s \prime\left(T b / 2 i k_{\gamma} s\right) e^{-s, z}\right)} \\
K_{z}=\frac{\left(\lambda^{\prime}+2 u^{\prime 2}\right)\left[-k^{\prime 2} T e^{-r^{\prime} z}+T r^{\prime 2} e^{-r, z}\right]-2 \mu^{\prime}\left[-k_{\gamma}^{2} T e^{-r^{\prime} z}-\left(T b / 2 i k_{\gamma} s\right) i k_{\gamma}^{\prime} s e^{-r^{\prime} z}\right]+m^{\prime} w^{\prime 2}\left(r^{\prime} T e^{-r^{\prime} z}+i k_{\gamma}^{\prime}(T b / 2 i k s) e^{-s^{\prime} z}\right)}{-\left(r e^{-r z}+(b / 2 s) e^{-s z}\right)+\left(r R e^{-r z}+i k(R b / 2 i k s) e^{-s z}\right)+\left(r^{\prime} T e^{-r^{\prime} z}+\left(T b k_{\gamma}^{\prime} / 2 k s\right) e^{-s^{\prime} z}\right)},
\end{gathered}
$$

where $r^{2}=k_{\gamma}{ }^{2}-k_{\alpha}{ }^{2}, \quad s^{2}=k_{\gamma}{ }^{2}-k_{\beta}{ }^{2}, c^{2}=2 r^{2}+k_{\beta}{ }^{2}$, and $b^{2}=2 s^{2}+k_{\beta}^{2}$.

$Z$ is the distance from the contact surface to the free surface. In this paper, the building is placed on the site soil surface, so the value $Z$ is $0 . \lambda$ and $\mu$ are lame coefficient. $k_{\alpha}, k_{\beta}$, and $k_{\gamma}$ are $\mathrm{P}$ wave, $S_{V}$ wave, and $R$ wave number, respectively. $T$ and $R$ are wave transmission coefficient. The letters with "' superscript are all the parameter characteristics of building foundation, and the definition of parameters is the same as that of soil. These parameters can be obtained by experiment before calculation.

The calculation results $K_{X}$ and $K_{\mathrm{z}}$ obtained by formulae (4) and (5) are spring stiffness corresponding to unit soil area. The spring stiffness in the model is determined by the average area of the four soil elements around the spring element and the spring stiffness coefficient $K_{X}$ or $K_{z}$. The 


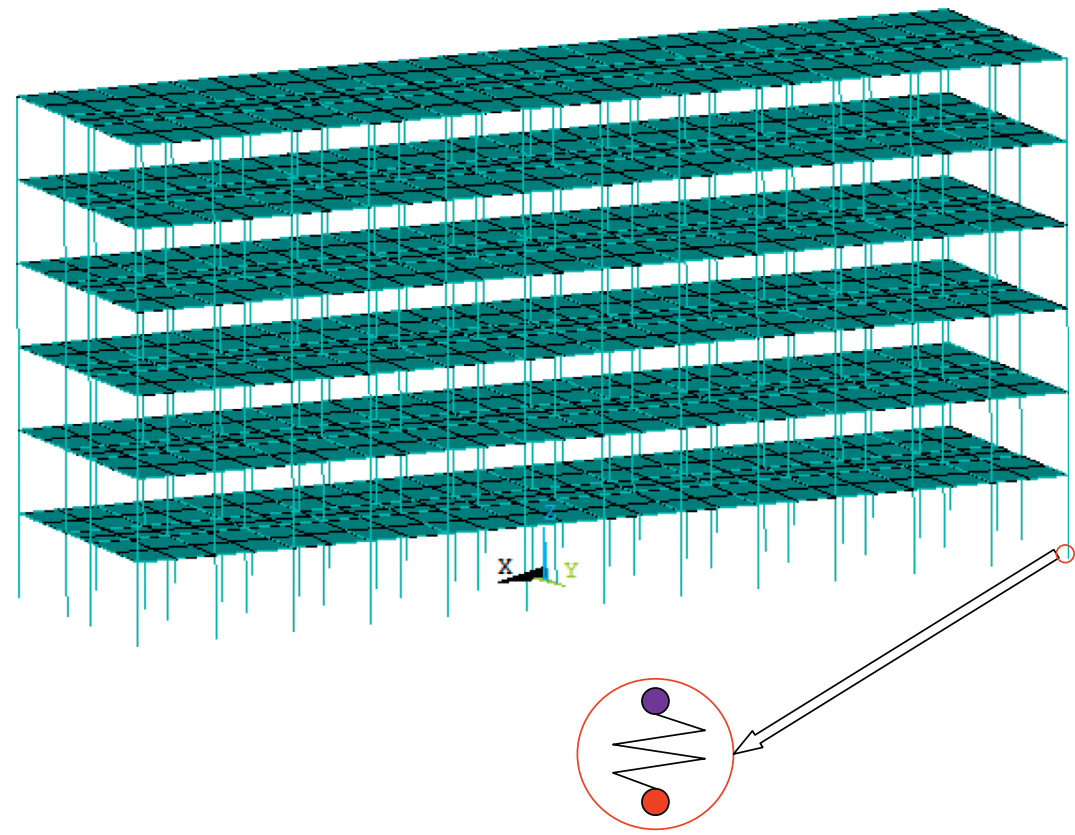

Figure 5: Three-dimensional finite element model of the building.

stiffness of each spring element in the model is the product of the spring stiffness coefficient and the average area of the four elements around the node. In this paper, the $x$-axis and $y$-axis of the coordinate system are perpendicular to each other, the $x$-axis and $y$-axis are parallel to the Earth's surface, and the $z$-axis is perpendicular to the Earth's surface. Therefore, the spring stiffness coefficient in the $y$-axis direction is the same as that in the $x$-axis direction.

The train-track model calculates the dynamic reaction force of the track. And then the reaction is put on the finite element model of the site soil. The displacement, velocity, and acceleration of any point on the site soil can be obtained. The building model is loaded by the mass method, and the mass is taken as the structural quality 1E6 times [25]. The product of the vibration acceleration and the concentrated mass is the force between the soil and the building. By analyzing the finite element model of the building, the vibration response of the building can be obtained.

The site soil and building are modeled independently for calculation and analysis. Through the calculation of the site model, the vibration response of each node in the site model can be obtained. When the building is loaded, the vibration acceleration of the node corresponding to the center of the building in the site model is extracted, and then the extracted vibration acceleration is loaded to the node at the bottom of all the columns of the building according to the large mass method.

\section{Analysis on Building Vibration Influence Factors}

In order to analyze the influence of train speed, axle load, distance, soil damping ratio, density, elastic modulus,
Poisson's ratio, and so on on the building vibration caused by the moving train, these parameters need to be analyzed. The analysis adopts the controlled variable method and only adjusts the vital parameters like vehicle speed, train axle load, distance from buildings, and site soil characteristics. Other parameters remain unchanged, the middle point of each layer is selected as the calculation point, and the vibration level $(\mathrm{dB})$ is used as the evaluation index. Various parameters are shown in Table 3.

3.1. Influence of Vehicle Speed. Select the train speed as $67 \mathrm{~km} / \mathrm{h}, 100 \mathrm{~km} / \mathrm{h}, 134 \mathrm{~km} / \mathrm{h}, 167 \mathrm{~km} / \mathrm{h}$, and $252 \mathrm{~km} / \mathrm{h}$. Figure 6 shows the curve of the acceleration vibration level of the building floor under different train speeds.

It can be seen from Figure 6 that when other conditions remain unchanged and when the train speed is $167 \mathrm{~km} / \mathrm{h}$, the vibration of the building is the smallest. When the train speed is $252 \mathrm{~km} / \mathrm{h}$, the vibration of the building is the largest. When the height increases, the change of vibration is not obvious, and the vibration of the building generally shows a trend of increasing with the increase of speed.

3.2. The Impact of Train Axle Load. Axle load is selected for the train. Five cases as $122 \mathrm{kN}, 128 \mathrm{kN}, 144 \mathrm{kN}, 160 \mathrm{kN}$, and $176 \mathrm{kN}$ are selected for analysis. Figure 7 shows the vibration acceleration level of the building floor with different train axle loads.

It can be seen from Figure 7 that, with the increase of the train axle load, the vibration level of the same measuring point on the building floor gradually increases. The train axle load has a certain influence on the building vibration. When the train axle load increases from $122 \mathrm{kN}$ to $176 \mathrm{kN}$, the vibration level changes about $3 \mathrm{~dB}$. 
TABLE 3: The values of parameters.

\begin{tabular}{lccccccccc}
\hline $\begin{array}{l}\text { The train } \\
\text { model }\end{array}$ & Speed & $\begin{array}{c}\text { Axle } \\
\text { load }\end{array}$ & $\begin{array}{c}\text { Poisson's } \\
\text { ratio }\end{array}$ & $\begin{array}{c}\text { Building } \\
\text { prediction point } \\
\text { distance }\end{array}$ & $\begin{array}{c}\text { Damping ratio } \\
\text { (two layers) }\end{array}$ & $\begin{array}{c}\text { Elastic } \\
\text { modulus } \\
\text { (layer 1) }\end{array}$ & $\begin{array}{c}\text { Elastic } \\
\text { modulus } \\
\text { (layer 2) }\end{array}$ & $\begin{array}{c}\text { Density } \\
\text { (layer 1) }\end{array}$ & $\begin{array}{c}\text { Density } \\
(\text { layer 2) }\end{array}$ \\
\hline $\mathrm{CRH} 2$ & $\begin{array}{c}67 \\
(\mathrm{~km} / \mathrm{h})\end{array}$ & $\begin{array}{c}160 \\
(\mathrm{kN})\end{array}$ & 0.20 & $16.57(\mathrm{~m})$ & 0.05 & $17.7(\mathrm{MPa})$ & $16.9(\mathrm{MPa})$ & $\begin{array}{c}1.83 \\
\left(\mathrm{~g} / \mathrm{cm}^{3}\right)\end{array}$ & $\begin{array}{c}2.02 \\
\left(\mathrm{~g} / \mathrm{cm}^{3}\right)\end{array}$ \\
\hline
\end{tabular}

3.3. Influence of Distance from Building. The distances from the building to the track center are selected as $10 \mathrm{~m}, 20 \mathrm{~m}$, $33 \mathrm{~m}, 41 \mathrm{~m}$, and $50 \mathrm{~m}$, and the vibration level is loaded onto the model by building a large mass method. Figure 8 is the vibration level of different floors with different distances from the building.

It can be seen from Figure 8 that distance has a significant effect on building vibration. Under the same distance, the vibration level between different floors is not much different, but as the distance increases, the building vibration level caused by the train gradually decreases, and the decrease in vibration level is very obvious.

\subsection{Site Soil Characteristics}

3.4.1. Influence of Soil Damping Ratio. The soil with damping ratios of $0.05,0.1,0.15,0.2$, and 0.25 is selected for calculation and analysis. The train speed is $67 \mathrm{~km} / \mathrm{h}$, axle load is $160 \mathrm{kN}$, and the other conditions remain unchanged. Figure 9 shows the variation curve of the acceleration vibration level of the building floor under different site soil damping ratio conditions.

It can be seen from Figure 9 that, with the increase of the site soil damping ratio, the floor vibration level gradually decreases, and the vibration level difference of the same calculation point is about $7 \mathrm{~dB}$; as the damping ratio increases (from 0.05 to 0.10 ), the vibration level of the same point is different. The maximum vibration level of the same computing points also changes with the increase in the damping ratio (from 0.20 to 0.25 ).

3.4.2. Influence of Soil Elastic Modulus. The multiples of the elastic modulus of the two layers are the same, and the multiples are multiplied by the elastic modulus values in Table 3, respectively, which are 0.1 times, 1 time, 10 times, 20 times, and 30 times. Figure 10 shows the fold change of the ground soil different elastic moduli and the vibration acceleration level of the building floor with floor layers' curve.

It can be concluded from Figure 10 that the vibration of the building does not increase monotonously with the increase of the soil elastic modulus. When the soil elastic modulus is 1 time, the vibration level of each floor calculation point is the largest. When the soil elastic modulus is 30 times, each floor vibration level is the minimum.
3.4.3. Influence of Soil Density. Due to the large difference in soil layers, it is difficult to analyze with the same numerical value. The density of soil changes by the same multiple, and the product of multiples is taken as the standard of the soil density in Table 3. Take 0.75 times, 1 time, and 1.25 times, 1.5 times, and 1.75 times. Figure 11 shows the curve of the acceleration vibration level of the building floor with the floor under different density changes of the site soil.

It can be seen from Figure 11 that, with the increase of soil density, the vibration level of the same calculation point gradually decreases; for the same soil density change, the vibration level of the same calculation point changes greatly when the soil density is small.

3.5. Test Analysis. Because numerical simulation needs to make idealized assumptions on the model to achieve the purpose of simplifying the model, there is an error between the numerical simulation results and the real vibration response. The field test data is the real vibration response, and the data results incorporate various influencing factors. Based on the Random Forest, the prediction model is deeply optimized using field test data to improve the accuracy of prediction.

The test site is located in a residential building near the Beijing-Guangzhou line. Passenger trains and freight trains are running on the line at the same time (this paper only analyzes the vibration response caused by passenger trains), the axle load of passenger trains is $160 \mathrm{kN}$, and the speed is between 40 and $115 \mathrm{~km} / \mathrm{h}$.

The residential building at the test site is a 6-storey brick-concrete structure, with a total height of $17.25 \mathrm{~m}$, a length of $58 \mathrm{~m}$ in the direction perpendicular to the line, and a width of $12 \mathrm{~m}$ in the direction parallel to the line. The distance between the building and the side rail of the line is $14 \mathrm{~m}$. Each building has 4 units. The distance to the line is 4 , 3,2 , and 1 units in order from far to near, the distance between each unit is $14.5 \mathrm{~m}$, there is no basement, the storey height is $2.8 \mathrm{~m}$, and each floor is made of $120 \mathrm{~mm}$ thick C25 cast-in-place concrete; the site layout is shown in Figure 12. The soil parameters are obtained by drilling and sampling in the laboratory. The soil quality parameters of the site where the building is located are shown in Table 4.

The measuring points are arranged on each floor of unit 4 of the building, as shown in Figure 13. Each measuring 


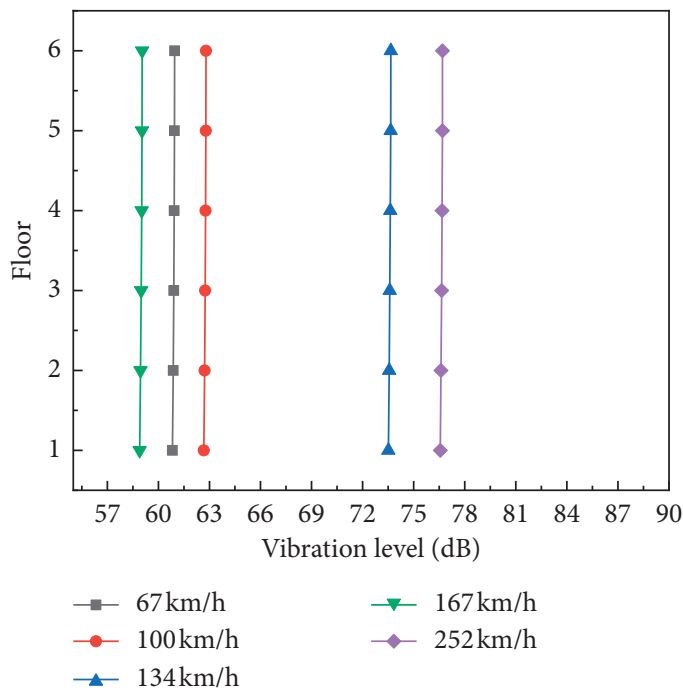

Figure 6: Building vibration of different floors under different vehicle speeds.

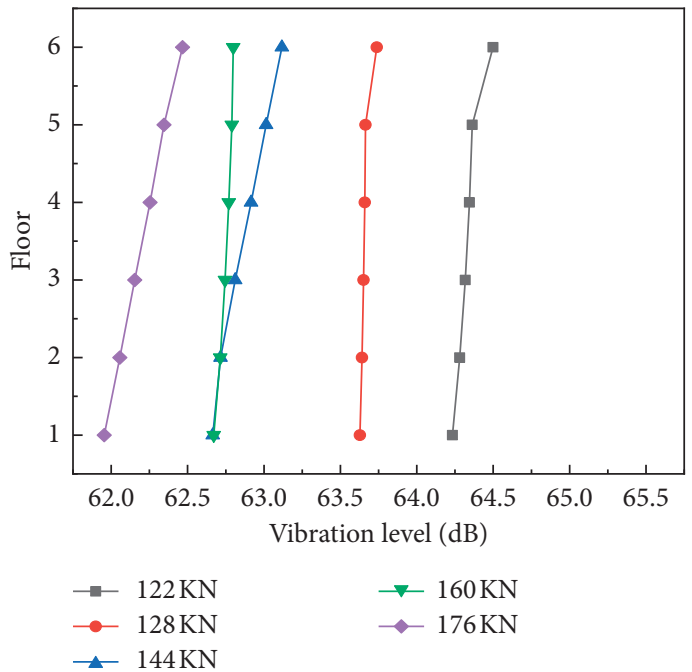

FIGURE 7: Building vibration with different floors under different axle loads.

point is equipped with vibration sensors in $X, Y$, and $Z$ directions (this paper only analyzes the vibration response in the $Z$ direction).

The sensor adopts 891-IV-type sensor produced by Harbin Gongli Institute. The acquisition instrument adopts INV303/306 made by Dongfang Vibration and Noise Technology Research Institute, and the sampling frequency is $100 \mathrm{~Hz}$. All instruments and sensors are debugged and calibrated before speed measurement.

The test collected 25 sets of data that can be used in this paper. After the collected vibration acceleration data is filtered and smoothed, Fourier transform is performed on the collected data, and the transformed data is analyzed by $1 / 3$ octave frequency, and then it is processed and converted into a vibration acceleration level, and the processed data is used in the training of the Random Forest program.
3.6. Data Processing. The data obtained from the field test and numerical simulation is the vibration acceleration, and the data is processed and converted into a form with the vibration level as the evaluation standard. The calculation of vibration level is shown in formula (6):

$$
L_{a}=20 \times \log _{10}\left(\frac{a}{a_{\text {ref }}}\right) .
$$

In formula (6), $L_{a}$ is the vibration level $(\mathrm{dB}) ; a_{\mathrm{ref}}$ is the reference vibration acceleration, which takes the value $1 \times 10^{-6} ; a\left(\mathrm{~m} / \mathrm{s}^{2}\right)$ is the root mean square vibration acceleration (RMS); the calculation equation (7) is as follows:

$$
a=\sqrt{\sum a_{f_{\mathrm{rms}}}^{2} \cdot 10^{0.1 c_{f}}}
$$




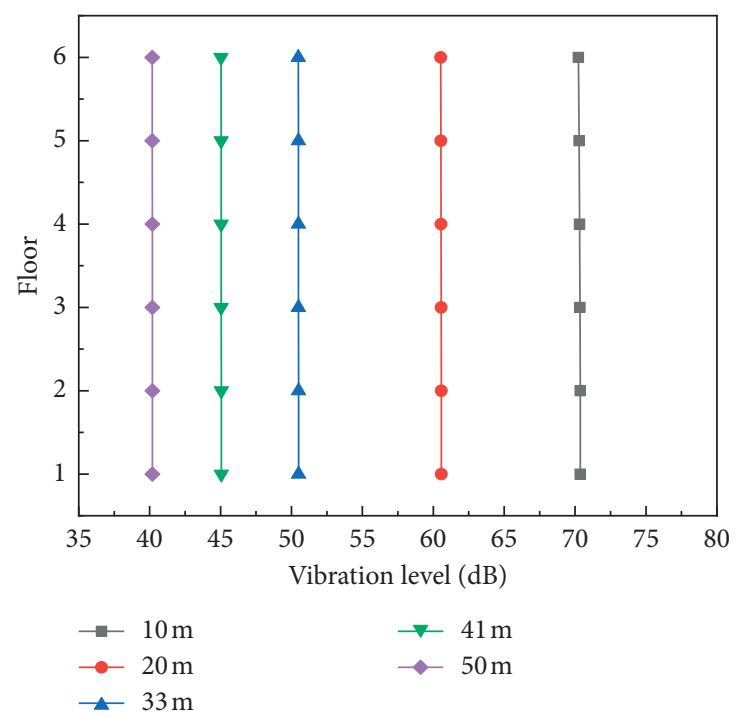

Figure 8: The vibration level of different floors with different distances from the building.

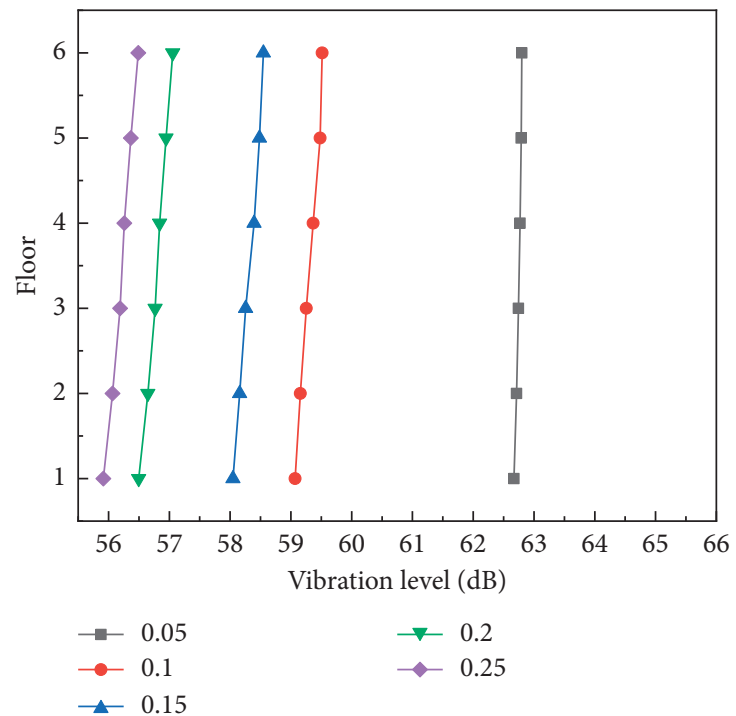

FiguRE 9: Variation curve of building vibration with floor under different damping ratios.

In formula (7) in, $a_{\text {frms }}$ is the frequency $f$ vibration acceleration (RMS), in units of $\mathrm{m} / \mathrm{s}^{2} ; c_{f}$ is corresponding to a different frequency vibration acceleration correction value.

\section{Random Forest Prediction Model}

4.1. Algorithm Development. The Random Forest was first proposed by Breiman [26] and others. Through the learning of existing data, the regression prediction of unknown data is realized, and the accuracy of prediction is improved through the integrated method of decision trees. In this paper, regression tree is used as the base regressor for integration. Each decision tree is independent of each other and can be calculated in parallel.
4.1.1. Building a Decision Tree. After the bagging method is used in the overall training set to collect a subset of training samples for each decision tree, each decision tree is trained to form a Random Forest. Each decision tree is trained independently, and no pruning is performed.

The CART [27] algorithm is selected as the decision tree node splitting method, and the C ART algorithm uses the minimum mean square error sum as the calculation index for node splitting. The calculated attributes of each node are selected at random instead of all attributes, so as to effectively reduce the generalization error.

The specific calculation method of CART is as follows: for any partition characteristic $A$, the corresponding arbitrary partition point $s$ is divided into data sets $D_{1}$ and $D_{2}$ on 


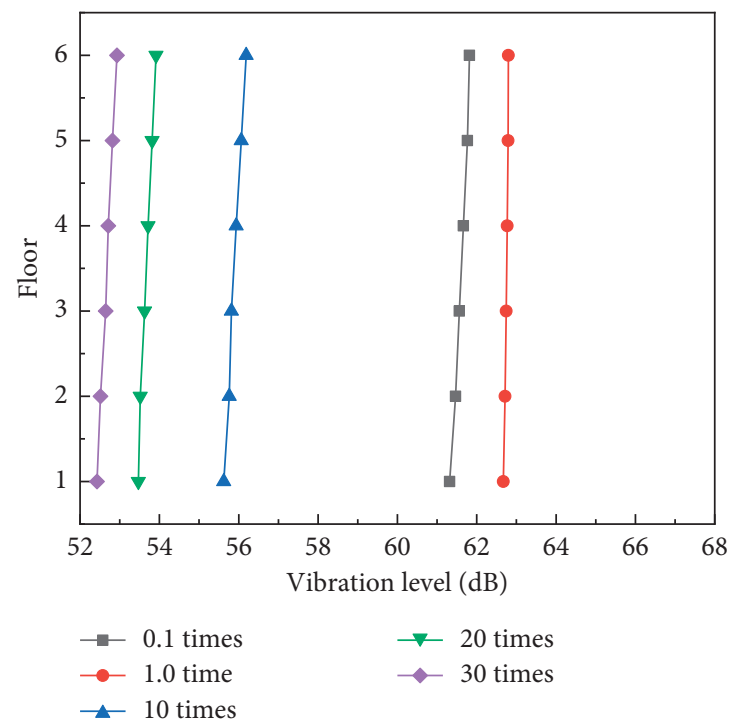

FIGURE 10: Variation curve of building vibration with floor under different soil elastic moduli.

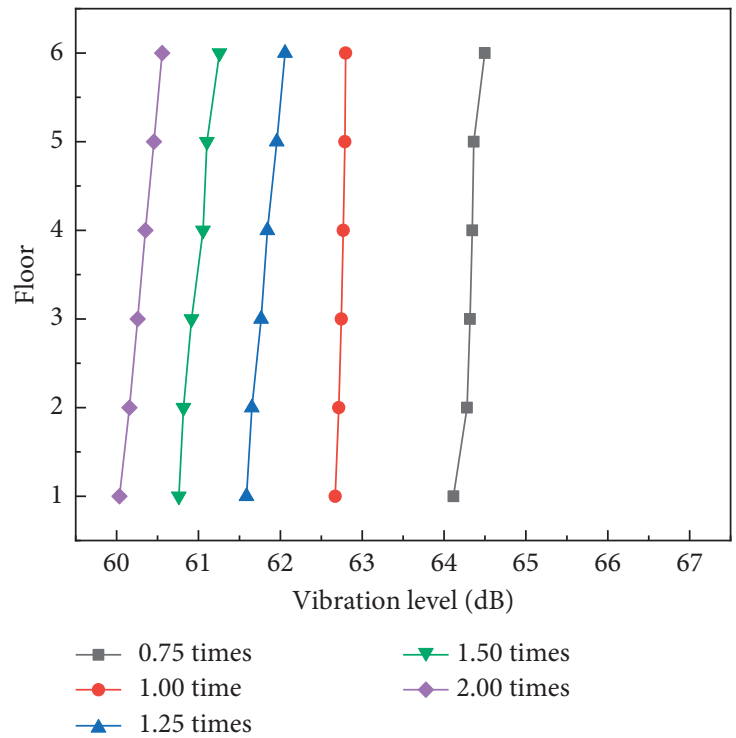

FIGURE 11: Variation curve of building vibration response with floor under different soil densities.

both sides, when the mean square error of each set of $D_{1}$ and $D_{2}$ is the smallest, and $D_{1}$ and $D_{2}$ are the variances of the corresponding characteristic minimum feature value and the division point. The expression is shown in formula (8):

$$
\min \left[\min \sum_{x_{i} \in D_{1}(A, s)}\left(y_{i}-c_{1}\right)^{2}+\min \sum_{x_{i} \in D_{2}(A, s)}\left(y_{i}-c_{2}\right)^{2}\right] \text {. }
$$

In formula (8), $\min \sum_{x_{i} \in D_{1}(A, s)}\left(y_{i}-c_{1}\right)^{2}$ is the $D_{1}$ sample output value data set; $\min \sum_{x_{i} \in D_{2}(A, s)}\left(y_{i}-c_{2}\right)^{2}$ is the $D_{2}$ sample mean output data set.

The prediction of the C ART tree outputs the prediction result based on the average value of the leaf nodes, so the prediction of the Random Forest is the average of the predicted values of all trees.

In this paper, the method of randomly combining input variables is selected as the method of random feature selection, and multiple input variables are selected to determine the random feature by linear combination. At the node, each input variable is linearly added with the coefficient as the weight to generate $n$ linear combinations, and then the CART algorithm is selected to split.

4.1.2. Algorithm Formation. The Random Forest model is written by MATLAB. The process of building the model is as follows: 


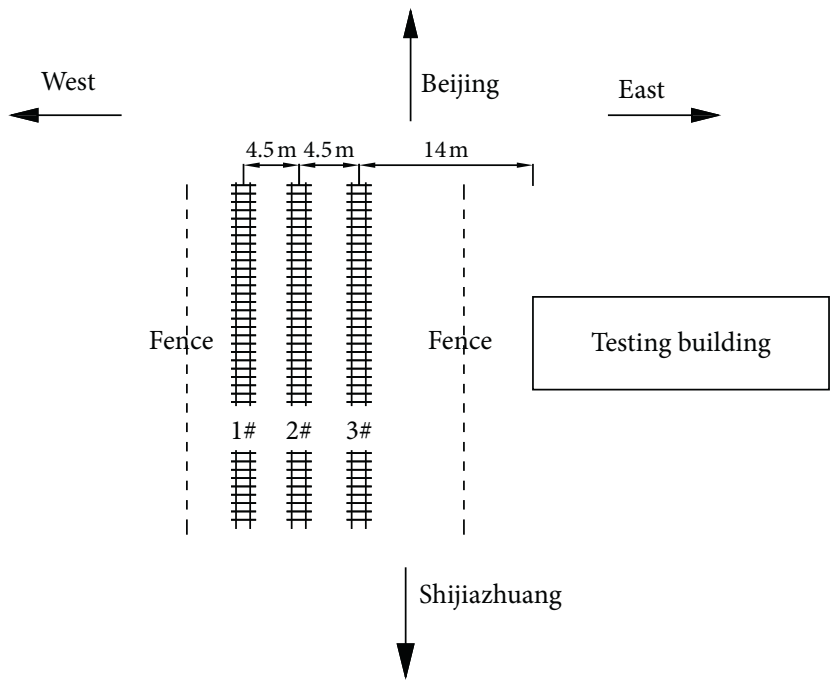

FIGURE 12: The schematic diagram on-site.

TABLe 4: Soil quality parameters of the site.

\begin{tabular}{lccccc}
\hline Soil layer & Thick $(\mathrm{m})$ & Bearing capacity $(\mathrm{kPa})$ & Compression modulus $(\mathrm{MPa})$ & Water content $(\%)$ & Density $\left(\mathrm{g} / \mathrm{cm}^{3}\right)$ \\
\hline Silty clay & $0.5-2.0$ & 150 & 17.0 & 19.6 & 24.0 \\
Silt & $2.0-2.4$ & 130 & 17.5 & 21.2 & 1.91 \\
Silty clay & $2.0-2.3$ & 150 & 17.5 & 22.1 & 1.75 \\
Silt & $2.2-3.0$ & 160 & 18.5 & 22.5 & 1.90 \\
Coarse sand & $1.9-2.5$ & 200 & 18.0 & 22.0 & 1.95 \\
Medium-coarse sand & $5.4-5.6$ & 320 & 22.0 & 2.11 \\
Silt & $2.8-30.0$ & 150 & 16.5 & 23.6 & 1.90 \\
\hline
\end{tabular}

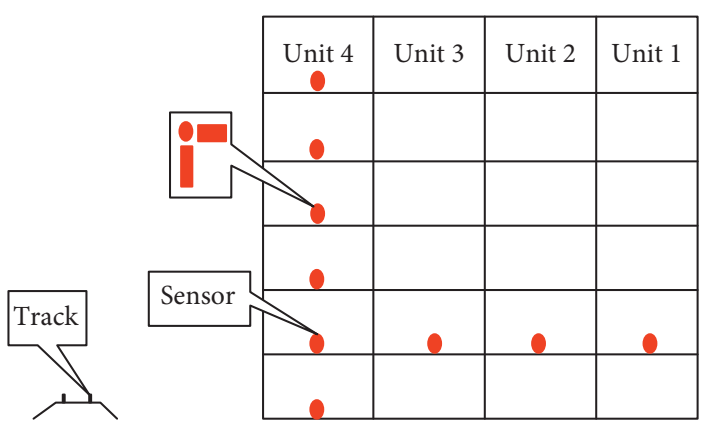

Figure 13: Building sensor layout.

(1) Random sampling is performed from the training samples using the bootstrapping method. The sampling takes the form of replacement. Five samples are taken each time, and a total of 1736 samples are taken. Generate 1736 training sets.

(2) Train the corresponding decision tree models on 1736 data sets, respectively, and train 1736 times in total.

(3) In each decision tree model, the number of features of the training sample is randomly selected. Assuming that the number of features is $n$, then the
CART algorithm is used to select the optimal feature for each split and then split.

(4) Each tree is split according to the above method until all the training samples on the node are of the same type.

(5) Combine each generated decision tree model to form a Random Forest. The predicted value is calculated through each tree, and then the predicted value of each tree is averaged to determine the final prediction result. Figure 14 shows the procedure of the training of the proposed RF model. 


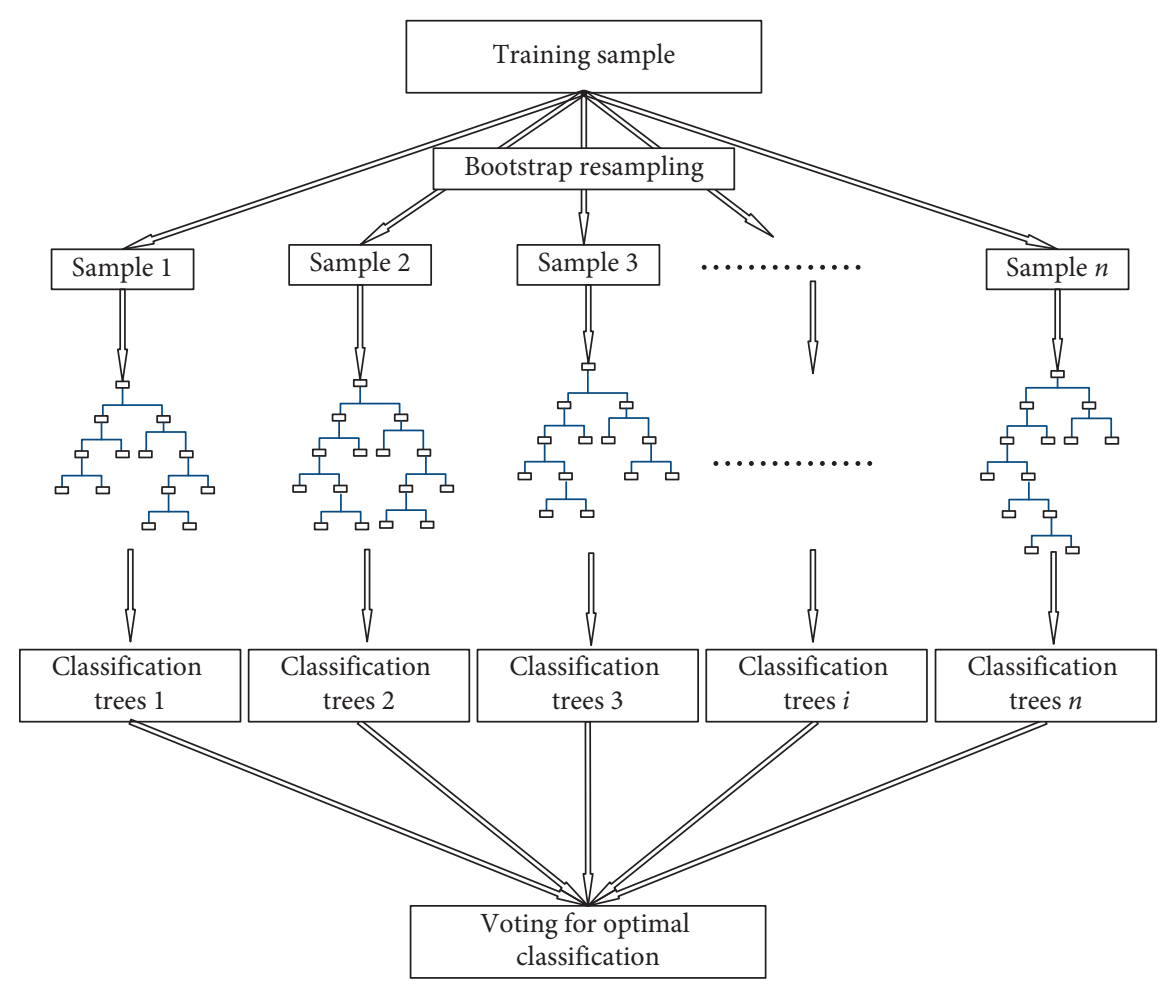

Figure 14: Process chart of Random Forest algorithm.

(6) After changing the number of random forests, repeat the above 1 5 steps and select the best number of random forests as 1320 .

4.2. Parameter Selection. In order to improve the calculation efficiency and shorten the calculation time, only the two soil characteristics that have the greatest impact on vibration are considered in the algorithm. In the sensitivity analysis of soil characteristic parameters, all parameters in the finite element model remain unchanged except for the characteristic parameters of the two-layer site soil (excluding the roadbed) in the site model.

The single variable method is used to analyze the sensitivity of each parameter. The damping ratio, Poisson's ratio, elastic modulus, and density parameter values of the site soil were increased by $15 \%$, and other parameters remained unchanged. Load the train wheel-rail force into the three-dimensional finite element model for calculation and analysis, and the acceleration time history data can be obtained and converted into vibration level. Compare the vibration level value after each parameter change with the result before the parameter unchanged, and then the difference is recorded. The parameter is used to represent the sensitivity. The sensitivity analysis of different parameters of the site soil is shown in Figure 15.

It can be seen from Figure 15 that, among all the parameters of the site soil, the soil damping ratio has the greatest impact on the building vibration, followed by the density. Therefore, the damping ratio and density are chosen to represent the characteristics of the soil.

4.3. Instance Verification. Select site soil vibration for prediction. Choose one of the working conditions to compare the test results, numerical model calculation results, and Random Forest prediction results. The working condition is that the train speed is $67 \mathrm{~km} / \mathrm{h}$, the train axle load is $160 \mathrm{kN}$, the upper soil elastic modulus is $17.7 \mathrm{MPa}$, and the lower soil elastic modulus is $16.9 \mathrm{MPa}$. The comparison result is shown in Figure 16.

According to Figure 16, we can get the following:

(1) The difference between the predicted value obtained by the Random Forest method and the simulated value obtained by the numerical simulation method is small, the maximum error is $2.35 \%$, and the average error is $0.72 \%$.

(2) The maximum error between the predicted value of the Random Forest method and the experimental data is $6.41 \%$, and the average error is $2.29 \%$, which is $1.19 \%$ and $0.58 \%$ lower than the error between the numerical simulation value and the experimental value, respectively. The results show that the Random Forest model can obtain data with higher accuracy than numerical simulation and can objectively reflect the law of propagation in the soil.

(3) As the weight of experimental data in the total 


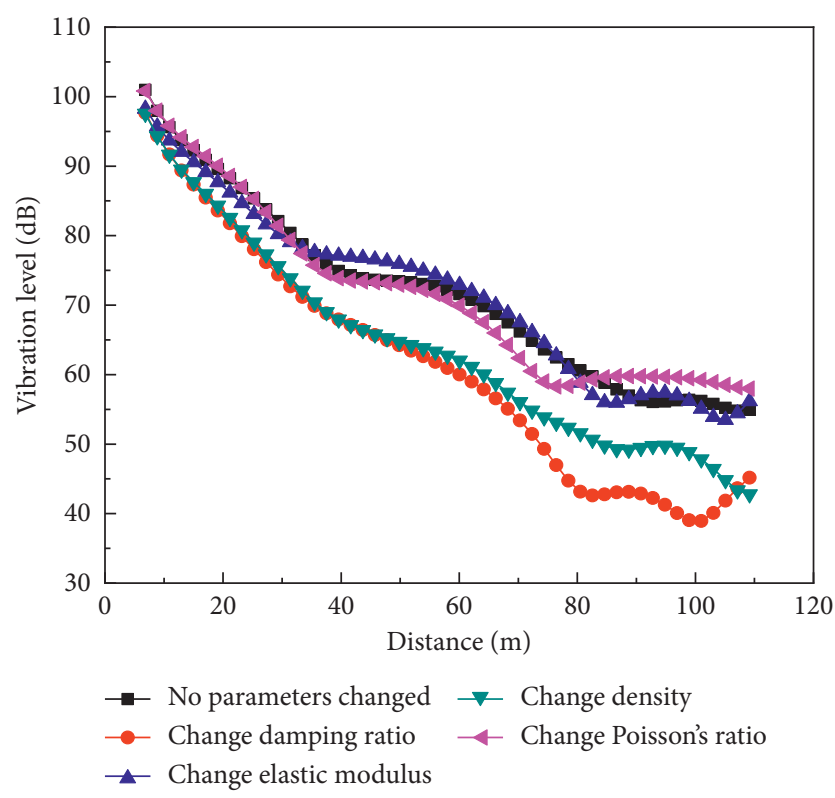

FIgURe 15: Parameter sensitivity analysis.

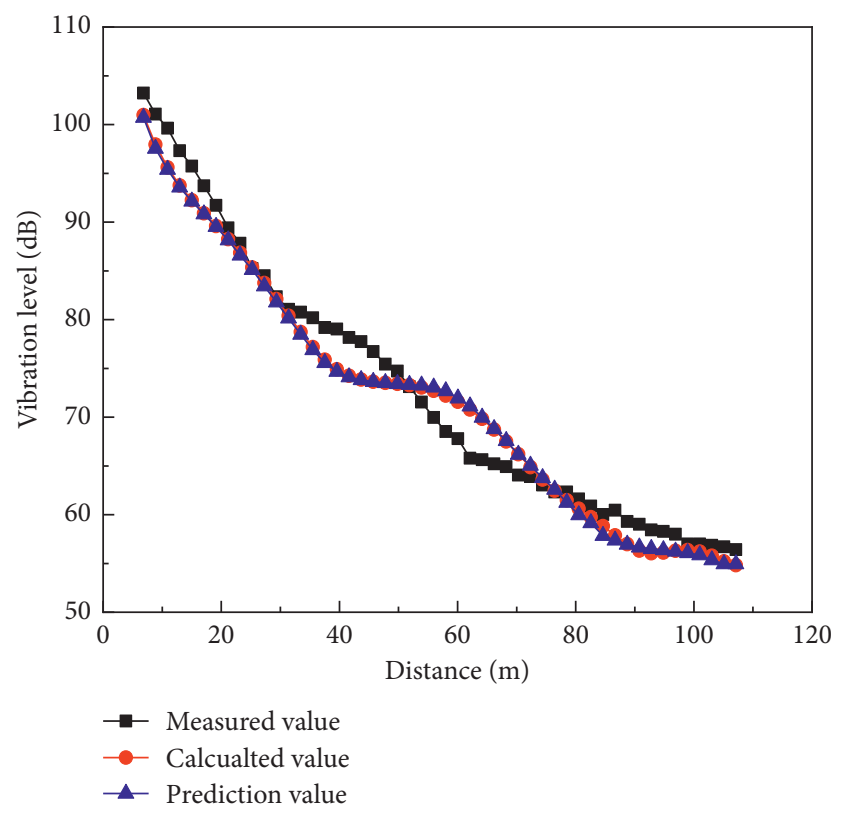

FIGURE 16: Comparison of the actual measured value, calculated value, and predicted value.

training sample is relatively small, the predicted value of Random Forest is closer to the calculated value of numerical simulation.

\section{Conclusions}

This paper uses a combination of numerical simulation, field test, and Random Forest to establish a prediction model of building vibration caused by trains. The prediction model is used to predict the environmental vibration under a certain working condition and compare it with the test results. The following can be obtained in conclusion:
(1) Numerical calculation results show that factors such as train speed, train axle load, distance between track and building, soil density, and soil damping have a greater impact on the environmental vibration response caused by high-speed trains.

(2) Simplify the multilayer soil structure of the site into two layers for modeling analysis, which can not only consider the influence of multilayer soil but also simplify the model.

(3) The method of combining the Random Forest with the three-dimensional finite element model and field test data can effectively make up for the shortcomings of the ideal assumption of the finite element model and insufficient field test data and improve the accuracy of prediction.

\section{Data Availability}

No data were used to support this study.

\section{Conflicts of Interest}

The authors declare that they have no conflicts of interest.

\section{Acknowledgments}

This research was supported by the China Postdoctoral Science Foundation (2020M680331) and the National Natural Science Foundation of China (51678032).

\section{References}

[1] H. Xia and Y. M. Cao, "Problem of railway traffic induced vibrations of environments," Journal of Railway Science and Engineering, vol. 1, no. 1, pp. 44-51, 2004.

[2] S.-J. Feng, X.-L. Zhang, Q.-T. Zheng, and L. Wang, "Simulation and mitigation analysis of ground vibrations induced by high-speed train with three dimensional FEM," Soil Dynamics and Earthquake Engineering, vol. 94, pp. 204-214, 2017.

[3] N. Correia dos Santos, J. Barbosa, R. Calçada, and R. Delgado, "Track-ground vibrations induced by railway traffic: experimental validation of a 3D numerical model," Soil Dynamics and Earthquake Engineering, vol. 97, pp. 324-344, 2017.

[4] H. Takemiya and X. C. Bian, "Shinkansen high-speed train induced ground vibrations in view of viaduct-ground interaction," Soil Dynamics and Earthquake Engineering, vol. 27, no. 6, pp. 506-520, 2007.

[5] M. Gao, S. P. Tian, Y. Wang, Q. S. Chen, and G. Y. Gao, "Isolation of ground vibration induced by high speed railway by DXWIB: field investigation," Soil Dynamics and Earthquake Engineering, vol. 131, pp. 131-140, 2020.

[6] G. Kouroussis, L. Van Parys, C. Conti, and O. Verlinden, "Prediction of ground vibrations induced by urban railway traffic: an analysis of the coupling assumptions between vehicle, track, soil, and buildings," International Journal of Acoustics and Vibration, vol. 18, no. 4, pp. 163-172, 2013.

[7] P. Coulier, G. Lombaert, and G. Degrande, "The influence of source-receiver interaction on the numerical prediction of railway induced vibrations," Journal of Sound and Vibration, vol. 333, no. 12, pp. 2520-2538, 2014.

[8] D. López-Mendoza, A. Romero, D. P. Connolly, and P. Galvín, "Scoping assessment of building vibration induced 
by railway traffic," Soil Dynamics and Earthquake Engineering, vol. 93, pp. 147-161, 2017.

[9] P. Galvín, D. L. Mendoza, D. P. Connolly, G. Degrande, G. Lombaert, and A. Romero, "Scoping assessment of freefield vibrations due to railway traffic," Soil Dynamics and Earthquake Engineering, vol. 114, pp. 598-614, 2018.

[10] X. Ding, L. Qu, J. Yang, and C. Wang, "Experimental study on the pile group-soil vibration induced by railway traffic under the inclined bedrock condition," Acta Geotechnica, vol. 15, no. 12, p. 3613, 2020.

[11] G. Paneiro, F. O. Durão, M. Costa e Silva, and P. Falcão Neves, "Artificial neural network model for ground vibration amplitudes prediction due to light railway traffic in urban areas," Neural Computing and Applications, vol. 29, no. 11, pp. 1045-1057, 2018.

[12] D. P. Connolly, G. Kouroussis, A. Giannopoulos, O. Verlinden, P. K. Woodward, and M. C. Forde, "Assessment of railway vibrations using an efficient scoping model," Soil Dynamics and Earthquake Engineering, vol. 58, no. 3, pp. 37-47, 2014.

[13] D. P. Connolly, G. Kouroussis, P. K. Woodward, A. Giannopoulos, O. Verlinden, and M. C. Forde, "Scoping prediction of re-radiated ground-borne noise and vibration near high speed rail lines with variable soils," Soil Dynamics and Earthquake Engineering, vol. 66, pp. 78-88, 2014.

[14] W. Shan, X. Chen, Y. He, and J. Zhou, "A novel experimental research on vibration characteristics of the running highspeed motorized spindles," Journal of Mechanical Science and Technology, vol. 27, no. 8, pp. 2245-2252, 2013.

[15] V. V. Krylov, "Generation of ground vibrations by superfast trains," Applied Acoustics, vol. 44, no. 2, pp. 149-164, 1995.

[16] V. V. Krylov, "Effects of track properties on ground vibrations generated by high-speed trains," Acta Acustica United with Acustica, vol. 84, no. 1, pp. 78-90, 1998.

[17] P. Jayawardana, D. P. Thambiratnam, N. Perera, and T. Chan, "Dual in-filled trenches for vibration mitigation and their predictions using artificial neural network," Soil Dynamics and Earthquake Engineering, vol. 122, pp. 107-115, 2019.

[18] J. Yao, H. Xia, N. Zhang, and B. Yu, "Prediction on building vibration induced by moving train based on support vector machine and wavelet analysis," Journal of Mechanical Science and Technology, vol. 28, no. 6, pp. 2065-2074, 2014.

[19] J. Yao, B. Yao, Y. Du, and Y. Jiang, "Train-induced vibration prediction in multi-story buildings using support vector machine," Neural Network World, vol. 24, no. 1, pp. 89-102, 2014.

[20] L. Fang, J. Yao, and X. He, "Prediction on soil-ground vibration induced by high-speed moving train based on artificial neural network model," Advances in Mechanical Engineering, vol. 2, no. 5, pp. 1-10, 2019.

[21] X. He and Z. Nan, Vehicle-Structure Dynamic Interaction, Science Press, Beijing, China, 2005.

[22] N. Hamdan, O. Laghrouche, P. K. Woodward, and M. S. Mahmood, "Ground vibration reduction analysis using a frequency-domain finite element approach," Construction and Building Materials, vol. 92, pp. 95-103, 2015.

[23] P. Brahma and S. Mukherjee, "A realistic way to obtain equivalent Young's modulus of layered soil," in Proceedings of the Indian Geotechnical Conference, pp. 305-308, Mumbai, India, December 2010.

[24] J. Liu, Y. Du, X. Du, Z. Wang, and J. Wu, "3D viscous-spring artificial boundary in time domain," Earthquake Engineering and Engineering Vibration, vol. 5, no. 1, pp. 93-102, 2006.
[25] P. Léger, I. M. Idé, and P. Paultre, "Multiple-support seismic analysis of large structures," Computers \& Structures, vol. 36, no. 6, pp. 1153-1158, 190.

[26] L. Breiman, "Random forests," Machine Learning, vol. 45, no. 1, pp. 5-32, 2001.

[27] B. S. Everitt, "Classification and regression tress," in Encyclopedia of Statistics Behavioral ScienceJohn Wiley \& Sons, Ltd., Hoboken, NJ, USA, 2005. 